\section{Crystal and Molecular Structure of a New Hydroxylamido/Amino Acid Oxovanadium(V) Complex, $\left[\mathrm{VO}\left(\mathrm{NH}_{2} \mathrm{O}\right)_{2}(\right.$ DL-methioninato $\left.)\right] \cdot \mathrm{H}_{2} \mathrm{O}$}

Oscar E. Piro ${ }^{\text {a }}$, Gustavo A. Echeverría ${ }^{a}$ Gabriel Arrambide ${ }^{\mathrm{b}}$, Dinorah Gambino ${ }^{\mathrm{b}}$, and Enrique J. Baran ${ }^{\mathrm{c}}$

a Departamento de Física and Instituto IFLP (CONICET), Facultad de Ciencias Exactas, Universidad Nacional de La Plata, 1900 La Plata, Argentina

b Química Inorgánica, Departamento "Estrella Campos", Facultad de Química, Universidad de la República, Montevideo, Uruguay

c Centro de Química Inorgánica (CEQUINOR, CONICET/UNLP), Facultad de Ciencias Exactas, Universidad Nacional de La Plata, C. Correo 962, 1900 La Plata, Argentina

Reprint requests to Dr. E. J. Baran.

E-mail: baran@quimica.unlp.edu.ar

Z. Naturforsch. 2011, 66b, 752-754; received April 20, 2011

The crystal and molecular structure of the $[\mathrm{VO}(\mathrm{DL}-$ meth $\left.\left(\mathrm{NH}_{2} \mathrm{O}\right)_{2}\right] \cdot \mathrm{H}_{2} \mathrm{O}$ complex has been determined by X-ray diffraction methods (monoclinic, $P 2_{1} / c$ with $a=5.8138(2)$, $b=27.3496(8), c=7.5663(2) \AA, \beta=103.059(3)^{\circ}$, and $Z=$ 4). The vanadium $(V)$ cation is in a pentagonal bipyramidal environment axially coordinated to the oxo group and equatorially to two hydroxylamido groups in a side-on fashion. The fifth equatorial binding site and the other apical position are occupied by an $\mathrm{N}$ and an $\mathrm{O}$ atom, respectively, from the methioninate anion acting as a bidentate ligand.

Key words: Oxovanadium(V) Complex, Amino Acid Complex, Hydroxylamido Complex, Crystal Structure

\section{Introduction}

Vanadium is one of the trace elements of which the essentiality for higher forms of life remains controversial [1-3]. Notwithstanding, it is well known that it plays an important role in certain metalloenzymes and in insulin regulation [1,3-6].

Peroxovanadium complexes received increasing attention during the last years because they are involved as intermediates in halide oxidation by vanadate- dependent peroxidases [1,3,6-8] and, additionally, some of them have interesting pharmacological properties $[9,10]$. In this context, renewed interest has also arisen on vanadium complexes with hydroxylamine, $\mathrm{NH}_{2} \mathrm{OH}$, a molecule which is isoelectronic with hydrogen peroxide, $\mathrm{H}_{2} \mathrm{O}_{2}$.

In a recent paper, we described the synthesis of a number of oxovanadium(V) complexes of the type $\left[\mathrm{VO}\left(\mathrm{NH}_{2} \mathrm{O}\right)_{2}\right.$ (amino acid)] and investigated in detail the vibrational-spectroscopic behavior of the hydroxylamido ligand present in them [11].

As structural information on this type of complexes remains relatively scarce, we have made efforts to attain single crystals of some of them adequate for X-ray diffraction studies. Usually, the obtained crystals are extremely small or of poor quality but, after several attempts with DL-methionine as the chelating amino acid, we could finally obtain a number of small, wellshaped, single crystals. Therefore, here we report the structure of the $\left[\mathrm{VO}\left(\mathrm{NH}_{2}\right)_{2}\right.$ (DL-met) $] \cdot \mathrm{H}_{2} \mathrm{O}$ complex.

\section{Experimental Section}

Synthesis of the complex

$\mathrm{NH}_{4} \mathrm{VO}_{3}, \mathrm{NaOH}$, and $\mathrm{NH}_{2} \mathrm{OH} \cdot \mathrm{HCl}$ were purchased from Merck, DL-methionine was obtained from Aldrich. All these reagents were used as supplied. Samples of the investigated complex were obtained by the general procedure previously outlined [11], as follows: $0.117 \mathrm{~g}(1.0 \mathrm{mmol})$ of $\mathrm{NH}_{4} \mathrm{VO}_{3}$ and $0.230 \mathrm{~g}(5.8 \mathrm{mmol})$ of $\mathrm{NaOH}$ were dissolved in $10 \mathrm{~mL}$ of distilled water, and the mixture was heated at $50{ }^{\circ} \mathrm{C}$ under stirring. After cooling to r.t., $0.463 \mathrm{~g}(3.1 \mathrm{mmol})$ of DL-methionine was added in small portions, under continuous stirring. The resulting solution was ice-cooled, and then $0.375 \mathrm{~g}(5.4 \mathrm{mmol})$ of $\mathrm{NH}_{2} \mathrm{OH} \cdot \mathrm{HCl}$ was added in small portions. After completion of the addition, the solution was kept for $5 \mathrm{~min}$. over ice and finally stored in a refrigerator at $3-$ $5{ }^{\circ} \mathrm{C}$. After a few hours the complex precipitated as a colorless microcrystalline powder, which was separated by filtration, washed with small portions of cold water and absolute ethanol, and finally dried under vacuum. Single crystals adequate for structural X-ray diffraction studies were selected from this mass, aided by a microscope.

The purity of the obtained material was confirmed by elemental analysis, using a Carlo Erba model EA 1108 elemental analyzer, as well as by IR and Raman spectroscopy [11]. $\mathrm{C}_{5} \mathrm{H}_{16} \mathrm{~N}_{3} \mathrm{O}_{6} \mathrm{SV}$ (297.21): calcd. C 20.19, H 5.38, N 14.13, S 10.78; found C 20.05, H 5.45, N 14,00, S 10.70 . 


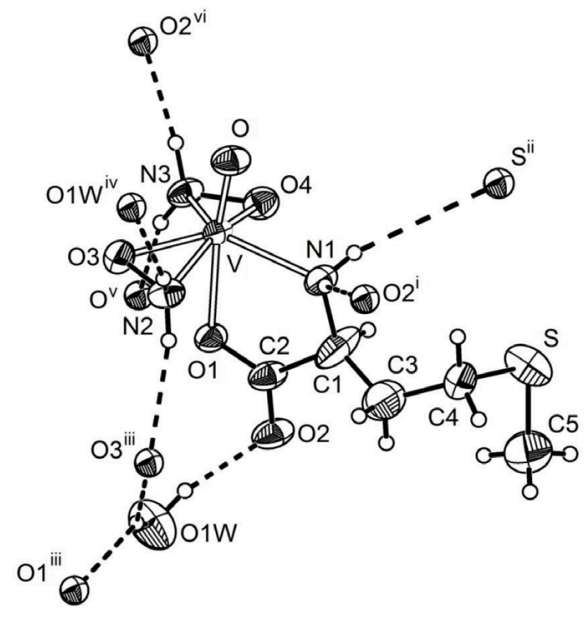

Fig. 1. ORTEP [15] view of one enantiomer in the crystal structure of $\left[\mathrm{VO}(\mathrm{DL}-\mathrm{meth})\left(\mathrm{NH}_{2} \mathrm{O}\right)_{2}\right] \cdot \mathrm{H}_{2} \mathrm{O}$ showing the labeling of the non- $\mathrm{H}$ atoms and their displacement ellipsoids at the $50 \%$ probability level. Metal-ligand bonds are indicated by open lines and hydrogen bonds by dashed lines. The symmetry operations used to generate equivalent atoms are i) $x-1, y, z$; ii) $-x,-y+1,-z$; iii) $x,-y+3 / 2, z-1 / 2$; iv) $x-1,-y+3 / 2, z+1 / 2$; v) $x+1, y, z$; vi) $x, y, z+1$.

\section{Crystal structure determination}

The measurements were performed on an Oxford Xcalibur, Eos, Gemini CCD diffractometer with graphite-monochromatized $\mathrm{Cu} K_{\alpha}(\lambda=1.54178 \AA)$ radiation. X-ray diffraction intensities were collected $(\omega$-scans with $\vartheta$ and $\kappa$ offsets), integrated and scaled with the CRYSALISPRO [12] suite of programs. The unit cell parameters were obtained by least-squares refinement based on the angular settings for all collected reflections with intensities larger than seven times the standard deviation of measurement errors. Data were corrected empirically for absorption employing the multi-scan method implemented in CRYSALISPRO. The structure was solved by Direct Methods with SHELXS-97 [13] and the molecular model refined by a full-matrix least-squares procedure on $F^{2}$ with SHELXL-97 [14]. Amino acid and water hydrogen atoms were located in a difference Fourier map and refined isotropically at their found positions. The water $\mathrm{Ow}-\mathrm{H}$ and $\mathrm{H} \cdots \mathrm{H}$ distances were constrained to target values of $0.86(1)$ and 1.36(1) $\AA$, respectively. The rest of the methioninato $\mathrm{H}$ atoms were refined employing the riding model with the methyl group treated as a rigid group allowed to rotate around the corresponding $\mathrm{C}-\mathrm{S}$ bond. A residual electron density of $1.8 \mathrm{e} \AA^{-3}$ in the final difference Fourier map is most probably due to positional disorder of the amino acid group around the $\mathrm{C}(1)$ atom arising from the fact that both enantiomers are present (with different occupancies) at the same site in the crystal. This is sustained by the observed sum of bond angles around $\mathrm{C}(1)$ of $344.3^{\circ}$, intermediate be-
Table 1. Crystallographic data and structure refinement details for $\left[\mathrm{VO}\left(\mathrm{NH}_{2} \mathrm{O}\right)_{2}\right.$ (DL-methioninato) $] \cdot \mathrm{H}_{2} \mathrm{O}$.

\begin{tabular}{|c|c|}
\hline Empirical formula & $\mathrm{C}_{5} \mathrm{H}_{16} \mathrm{~N}_{3} \mathrm{O}_{6} \mathrm{SV}$ \\
\hline Formula weight & 297.21 \\
\hline Temperature, $\mathrm{K}$ & $295(2)$ \\
\hline Crystal system & monoclinic \\
\hline Space group & $P 2_{1} / c$ \\
\hline$a, \AA$ & $5.8138(2)$ \\
\hline$b, \AA$ & $27.3496(8)$ \\
\hline$c, \AA$ & $7.5663(2)$ \\
\hline$\beta, \operatorname{deg}$ & $103.059(3)$ \\
\hline$V, \AA^{3}$ & $1171.97(6)$ \\
\hline$D_{\mathrm{c}}, \mathrm{g} \mathrm{cm}^{-3}$ & 1.65 \\
\hline$Z$ & 4 \\
\hline Crystal size, $\mathrm{mm}^{3}$ & $0.158 \times 0.078 \times 0.067$ \\
\hline Absorption coefficient, $\mathrm{mm}^{-1}$ & 9.0 \\
\hline$F(000), \mathrm{e}$ & 616 \\
\hline$\theta$ range for data collection, deg & $3.23-74.07$ \\
\hline Index ranges & $\begin{array}{l}-7 \leq h \leq 4,-34 \leq k \leq 33 \\
-7 \leq l \leq 9\end{array}$ \\
\hline Reflections collected & 7321 \\
\hline Independent reflections / $\mathrm{R}_{\mathrm{int}}$ & $2379 / 0.0263$ \\
\hline Observed reflections $[I \geq 2 \sigma(I)]$ & 2037 \\
\hline Data / restraints / parameters & $2379 / 4 / 178$ \\
\hline Goodness-of-fit on $F^{2}$ & 1.071 \\
\hline Final indices $R 1 / w R 2[I \geq 2 \sigma(I)]$ & $0.0609 / 0.1668$ \\
\hline Final indices $R 1 / w R 2$ (all data) & $0.0683 / 0.1715$ \\
\hline Largest diff. peak / hole, e $\AA^{-3}$ & $1.84 /-0.87$ \\
\hline
\end{tabular}

Table 2. Bond lengths ( $\mathrm{A})$ and angles (deg) around vana$\operatorname{dium}(\mathrm{V})$ in $\left[\mathrm{VO}\left(\mathrm{NH}_{2} \mathrm{O}\right)_{2}\right.$ (DL-methioninato) $] \cdot \mathrm{H}_{2} \mathrm{O}$.

\begin{tabular}{lrlr}
\hline $\mathrm{N}(1)-\mathrm{V}$ & $2.120(4)$ & $\mathrm{N}(2)-\mathrm{V}$ & $2.027(4)$ \\
$\mathrm{N}(3)-\mathrm{V}$ & $1.990(4)$ & $\mathrm{O}-\mathrm{V}$ & $1.600(3)$ \\
$\mathrm{O}(1)-\mathrm{V}$ & $2.175(3)$ & $\mathrm{O}(3)-\mathrm{V}$ & $1.907(3)$ \\
$\mathrm{O}(4)-\mathrm{V}$ & $1.919(3)$ & & \\
$\mathrm{O}-\mathrm{V}-\mathrm{O}(3)$ & $100.78(16)$ & $\mathrm{O}-\mathrm{V}-\mathrm{O}(4)$ & $101.71(16)$ \\
$\mathrm{O}(3)-\mathrm{V}-\mathrm{O}(4)$ & $133.53(14)$ & $\mathrm{O}-\mathrm{V}-\mathrm{N}(3)$ & $104.71(17)$ \\
$\mathrm{O}(3)-\mathrm{V}-\mathrm{N}(3)$ & $93.30(16)$ & $\mathrm{O}(4)-\mathrm{V}-\mathrm{N}(3)$ & $41.64(15)$ \\
$\mathrm{O}-\mathrm{V}-\mathrm{N}(2)$ & $97.22(17)$ & $\mathrm{O}(3)-\mathrm{V}-\mathrm{N}(2)$ & $41.80(14)$ \\
$\mathrm{O}(4)-\mathrm{V}-\mathrm{N}(2)$ & $161.02(16)$ & $\mathrm{N}(3)-\mathrm{V}-\mathrm{N}(2)$ & $133.42(17)$ \\
$\mathrm{O}-\mathrm{V}-\mathrm{N}(1)$ & $95.56(16)$ & $\mathrm{O}(3)-\mathrm{V}-\mathrm{N}(1)$ & $133.17(17)$ \\
$\mathrm{O}(4)-\mathrm{V}-\mathrm{N}(1)$ & $84.00(18)$ & $\mathrm{N}(3)-\mathrm{V}-\mathrm{N}(1)$ & $124.36(18)$ \\
$\mathrm{N}(2)-\mathrm{V}-\mathrm{N}(1)$ & $92.97(18)$ & $\mathrm{O}-\mathrm{V}-\mathrm{O}(1)$ & $170.40(15)$ \\
$\mathrm{O}(3)-\mathrm{V}-\mathrm{O}(1)$ & $82.19(13)$ & $\mathrm{O}(4)-\mathrm{V}-\mathrm{O}(1)$ & $82.27(13)$ \\
$\mathrm{N}(3)-\mathrm{V}-\mathrm{O}(1)$ & $84.11(14)$ & $\mathrm{N}(2)-\mathrm{V}-\mathrm{O}(1)$ & $78.83(14)$ \\
$\mathrm{N}(1)-\mathrm{V}-\mathrm{O}(1)$ & $76.05(13)$ & & \\
\hline & & &
\end{tabular}

tween the ideal tetrahedral $\left(328.5^{\circ}\right)$ and planar $\left(360^{\circ}\right)$ angles and also by the rather large displacement parameters of $\mathrm{C}(1)$ perpendicular to the $\mathrm{C}(1) \mathrm{NC}(2) \mathrm{C}(3)$ plane. This disorder is also reflected in a too short $\mathrm{C}(1)-\mathrm{C}(3)$ single bond length (1.429(9) $\AA$ ) on the side chain. Crystal data and structure refinement results are summarized in Table 1.

Tables containing complete information on fractional atomic coordinates and equivalent isotropic displacement parameters of the non- $\mathrm{H}$ atoms, atomic anisotropic displacement parameters, and hydrogen atom positions have been deposited at The Cambridge Crystallographic Data Centre un- 
der deposition number CCDC 826986. These data can be obtained free of charge via www.ccdc.cam.ac.uk/data_request/ cif.

\section{Results and Discussion}

An ORTEP [15] drawing of the [VO(DL-meth)$\left.\left(\mathrm{NH}_{2} \mathrm{O}\right)_{2}\right] \cdot \mathrm{H}_{2} \mathrm{O}$ complex is shown in Fig. 1. Intramolecular bond lengths and angles around the vanadium center are given in Table 2 .

The vanadyl $\mathrm{V}=\mathrm{O}$ bond $[\mathrm{d}(\mathrm{V}=\mathrm{O}) 1.601(3) \AA] \mathrm{de}-$ fines the axis of a distorted pentagonal bipyramidal environment around the vanadium( $(\mathrm{V})$ cation. The metal atom is equatorially coordinated in a side-on fashion to two hydroxylamido anions through both their oxygen [V-O distances of 1.908(3) and 1.918(3) $\AA$ ] and nitrogen atoms [V-N distances of 2.028(4) and 1.989(4) $\AA$ ] The remaining equatorial and axial coordination sites are bridged by the amino acid molecule acting as a bidentate ligand through its nitrogen atom $[d(\mathrm{~V}-\mathrm{N})$ $2.120(4) \AA]$ and one carboxylic oxygen atom $[d(\mathrm{~V}-\mathrm{O})$ $2.175(3) \AA]$.

The atoms equatorially coordinated to vanadium lie nearly on a common plane [rms deviation of atoms from the least squares plane of $0.015 \AA$ ] and at the rim of a Chinese umbrella-like shape that gently slopes down opposite to the $\mathrm{VO}$ bond direction [O(carboxyl)$\mathrm{V}-\mathrm{L}(\mathrm{eq})$ angles in the range from $76.0(1)$ to $\left.84.1(1)^{\circ}\right]$.
The conformation and intramolecular bond lengths and angles agree well with those of the few complexes of this type which have been structurally characterized, namely $\left[\mathrm{VO}\left(\mathrm{NH}_{2} \mathrm{O}\right)_{2}\right.$ (glycine) $] \cdot \mathrm{H}_{2} \mathrm{O}$ [16], $\left[\mathrm{VO}\left(\mathrm{NH}_{2} \mathrm{O}\right)_{2}\right.$ (serine)] $\mathrm{H}_{2} \mathrm{O}$ [16], [ $\mathrm{VO}\left(\mathrm{NH}_{2} \mathrm{O}\right)_{2}$ (alanine) $] \cdot 2 \mathrm{H}_{2} \mathrm{O}$ [17] and [ $\mathrm{VO}\left(\mathrm{NH}_{2} \mathrm{O}\right)_{2}$ (threonine)] [17]. It is interesting to mention that while in these latter compounds the two hydroxylamido ligands are coordinated with the nitrogen atoms $c i s$ to the remaining equatorial ligands $[16,17]$, in the present case these $\mathrm{N}$ ligands are in trans position to each other (see Fig. 1). It has been suggested that the steric requirements of the other equatorial ligands dictate the orientation of the hydroxylamido groups [16].

The solid is further stabilized by a complex network of intermolecular $\mathrm{N}-\mathrm{H} \cdots \mathrm{O}[\mathrm{N} \cdots \mathrm{O}$ distances of $2.85(5)$ and $3.12(5) \AA], \quad \mathrm{N}-\mathrm{H} \cdots \mathrm{S} \quad[\mathrm{d}(\mathrm{N} \cdots \mathrm{S})$ 3.68(5) $\AA$ ], $\mathrm{N}-\mathrm{H} \cdots \mathrm{Ow} \quad[\mathrm{d}(\mathrm{N} \cdots \mathrm{Ow}) \quad 2.77(6) \AA]$, and $\mathrm{Ow}-\mathrm{H} \cdots \mathrm{O}[\mathrm{Ow} \cdot \mathrm{O}$ distances of $2.85(5)$ and 3.14(6) $\AA$ ] hydrogen bonds (see Fig. 1).

\section{Acknowledgements}

This work was supported by the Universidad Nacional de La Plata, by CONICET (PIP 1529), and by ANPCyT (PME06 2804 and PICT06 2315) of Argentina. It is also a part of the CYTED network RIIDFCM (Red Temática 209 RT0380). O.E.P., G. A.E. and E. J.B. are members of the Research Career from CONICET.
[1] D. Rehder, Bioinorganic Vanadium Chemistry, J. Wiley, Chichester, 2008.

[2] E. J. Baran, J. Braz. Chem. Soc. 2003, 14, 878-888.

[3] D. C. Crans, J. J. Smee, E. Gaidamauskas, L. Yang, Chem. Rev. 2004, 104, 849-902.

[4] K.H. Thompson, C. Orvig, J. Chem. Soc., Dalton Trans. 2000, $2885-2892$.

[5] D. Rehder, Inorg. Chem. Commun. 2003, 6, 604-617.

[6] E. J. Baran in Advances in Plant Physiology (Ed.: H. Hemantaranjan), Vol. 10, Scientific Publishers, Jodhpur, 2007, pp. $357-372$.

[7] C. Slebodnick, B. J. Hamstra, V. L. Pecoraro, Struct. Bonding 1997, 89, $51-108$.

[8] A. Butler, Coord. Chem. Rev. 1999, 187, 17-35.

[9] C. Djordjevic in Metal Ions in Biological Systems (Eds.: H. Sigel, A. Sigel), Vol. 31, Marcel Dekker, New York, 1995, pp. 595-616.

[10] E. J. Baran, Acta Farm. Bonaerense 1997, 16, 43-52.

[11] G. Arrambide, D. Gambino, E. J. Baran, J. Coord. Chem. 2009, 62, 63-74.
[12] CRYSAlisPro (version 1.171.33.48; release 15-092009 CRYSALIS 171.NET), Oxford Diffraction Ltd., Oxford (U. K.) 2009.

[13] G. M. Sheldrick, SHELXS-97, Program for the Solution of Crystal Structures, University of Göttingen, Göttingen (Germany) 1997. See also: G. M. Sheldrick, Acta Crystallogr. 1990, A46, 467-473.

[14] G. M. Sheldrick, SHELXL-97, Program for the Refinement of Crystal Structures, University of Göttingen, Göttingen (Germany) 1997. See also: G. M. Sheldrick, Acta Crystallogr. 2008, A64, 112- 122.

[15] C. K. Johnson, ORTEP-II, A Fortran Thermal Ellipsoid Plot Program, Report ORNL-5318, Oak Ridge National Laboratory, Oak Ridge, TN (USA) 1976.

[16] A. D. Keramidas, S. M. Miller, O.P. Andersen, D. C. Crans, J. Am. Chem. Soc. 1997, 119, $8901-8915$.

[17] L.Z. Li, T. Xu, D. Q. Wang, J. Chem. Crystallogr. 2004, 34, 585-590. 